\title{
Componentes da Resistência à Mancha-Bacteriana e Crescimento de Xanthomonas campestris pv. vesicatoria, Raça T2, em Genótipos de Tomateiro*
}

\author{
Valácia L. da S. Lobo ${ }^{1 * *}$, Carlos A. Lopes² \& Leonardo de B. Giordano² \\ ${ }^{1}$ Departamento de Fitopatologia, Instituto de Ciências Biológicas, Universidade de Brasília, CEP 70919-900, Brasília, DF, \\ fax: (62) 5332100, e-mail: valacia@enpaf.embrapa.br; ${ }^{2}$ Embrapa Hortaliças, Cx. Postal 218, CEP 70359-970, Brasília, DF, \\ e-mails: clopes@cnph.embrapa.br, giordano@cnph.embrapa.br
}

(Aceito para publicação em 01/12/2004)

Autor para correspondência: Valácia Lemes da Silva Lobo

SILVA-LOBO, V.L., LOPES, C.A. \& GIORDANO, L.B. Componentes da resistência à mancha-bacteriana e crescimento de Xanthomonas campestris pv. vesicatoria, raça T2, em genótipos de tomateiro. Fitopatologia Brasileira 30:17-20. 2005.

\section{RESUMO}

Componentes da resistência e crescimento da população bacteriana de Xanthomonas campestris pv. vesicatoria (Xcv), raça T2, foram quantificados em genótipos de tomateiro (Lycopersicon esculentum) resistentes ('Ohio 8245', 'Agrocica 30' e 'Hawaii 7998') e suscetíveis ('CNPH 401-08'e 'CNPH 416.81.01.02'). A população bacteriana de Xcv evoluiu diferentemente em genótipos resistentes e suscetíveis, atingindo valor até 100 vezes maior no genótipo suscetível 'CNPH 401-08', sete dias após a inoculação. Os componentes de resistência avaliados foram tamanho de lesão, número de lesões, área lesionada e período latente. Os genótipos resistentes e suscetíveis diferiram estatisticamente entre si para todos os componentes avaliados, exceto para o diâmetro da lesão, onde somente o genótipo 'CNPH 416.81.01.02' diferiu dos genótipos resistentes. O período latente foi significativamente diferente em genótipos resistentes e suscetíveis no campo, casa de vegetação e câmara de crescimento, e variou entre seis e 11 dias. Tamanho de lesão não foi um bom indicador para separar genótipos quanto à resistência, por ser um caráter bastante influenciado pelo ambiente. O número de lesões e o período latente apresentaram-se como caracteres fáceis e rápidos de serem avaliados; estes componentes explicam, em grande parte, a resistência observada nos genótipos avaliados pelo sistema de notas.

Palavras-chave adicionais: período latente, tamanho de lesão, número de lesões, área lesionada, Lycopersicon esculentum.

\begin{abstract}
Resistance components to bacterial spot and growth of Xanthomonas campestris pv. vesicatoria, race $\mathrm{T} 2$, in tomato genotypes Resistance components and the growth of Xanthomonas campestris pv. vesicatoria (Xcv) were quantified on resistant ('Ohio 8245', 'Agrocica 30' and 'Hawaii 7998') and susceptible ('CNPH 401-08' and 'CNPH 416.81.01.02') tomato (Lycopersicon esculentum) genotypes. The bacterial population increased differently on resistant and susceptible groups of genotypes and it was about 100 times higher in the susceptible genotype 'CNPH 401-08', seven days after inoculation. The resistance components evaluated were lesion size, number of lesions, lesion area, and latent period. All the components of resistance were statistically different in resistant and susceptible genotypes, except for lesion size, which discriminated only 'CNPH 416.81.01.02' from resistant genotypes. The latent period varied from six to 11 days in susceptible and resistant genotypes when assessed in the field, greenhouse, and growth chamber. Lesion number and latent period were considered reliable components for evaluating resistance to bacterial spot, in contrast to lesion size, which was unstable and very dependent on environmental conditions.
\end{abstract}

Additional keywords: latent period, size of lesions, number of lesions, infected area, Lycopersicon esculentum.

\section{INTRODUÇÃO}

A mancha-bacteriana do tomateiro (Lycopersicon esculentum Mill.), causada por Xanthomonas campestris pv. vesicatoria (Doidge) Dye (Xcv), é uma doença de difícil controle, principalmente sob condições de altas temperaturas e umidade, nas quais o controle químico isolado é ineficiente. O melhor controle da doença é obtido por meio da combinação

*Parte da Tese de Doutorado do primeiro autor.. Universidade de Brasília (2000).

**Endereço atual: Embrapa Arroz e Feijão, Cx. Postal 179, CEP 75375000, Santo Antônio de Goiás, GO. de práticas culturais como, sementes e mudas livres do patógeno, limpeza da área, rotação de culturas, tratamento químico e uso de cultivares resistentes (Sahin \& Miller, 1996; Lopes \& Quezado-Soares, 1997).

Em programas de melhoramento, a resistência à doença normalmente é avaliada pela severidade e/ou desfolha. Outra recomendação para doenças de herança quantitativa, é a avaliação dos componentes de resistência, a qual pode ser feita medindo-se: incidência da doença; tamanho, número e/ ou tipos de lesão; tamanho e freqüência de estômatos; produção de esporos; período de incubação; período infeccioso; período latente (Plank, 1963; Somodi et al., 1991). 
Este último componente é bastante variável, podendo ser muito curto [quatro dias para Phytophthora infestans De Bary em batata (Solanum tuberosum L.)] ou bastante prolongado [quatro anos para Eutypa armenicae Tull \& C. Tull em ameixeira (Prunus salicina Lindl)]. Pode ainda, apresentar grandes variações entre grupos de patógenos ou dentro de um mesmo patossistema, estando estas diferenças associadas ao genótipo da espécie hospedeira, à raça do patógeno envolvido e das condições de ambiente (Amorim, 1995).

A resistência, geralmente, afeta mais a multiplicação do patógeno do que a sua disseminação. Durante o processo de avaliação de resistência a doenças, na maioria dos casos, os sintomas são avaliados de acordo com o que eles refletem quantitativamente, ou seja, a multiplicação do patógeno na planta hospedeira. Por isso, o monitoramento do crescimento da população de bactérias fitopatogênicas, em lesões ou mesmo antes do aparecimento dos sintomas da doença na planta, também é usado na diferenciação de genótipos quanto à resistência (Chand \& Walker, 1964; Stall \& Cook, 1966; Parlevliet, 1979; McGuire et al., 1991; Wang, 1992; Silva \& Lopes, 1995).

Os objetivos deste estudo foram: (a) avaliar os componentes de resistência tamanho e número de lesões, área lesionada e período latente, (b) monitorar o crescimento populacional de $\mathrm{Xcv}$, raça $\mathrm{T} 2$, em genótipos resistentes e suscetíveis de tomateiro.

\section{MATERIALE MÉTODOS}

Os genótipos 'Ohio 8245', 'Agrocica 30', 'Hawaii 7998', 'CNPH 401-08' e 'CNPH 416.81.01.02', previamente selecionados por apresentarem diferentes níveis de resistência à mancha-bacteriana (Silva et al., 1998a, 1998b), foram utilizados no monitoramento da curva de crescimento, avaliação do tamanho e número de lesões, área lesionada e período latente de Xcv, raça T2.

Para o monitoramento da curva de crescimento de Xcv, folíolos de plantas com 15 dias após o transplantio (DAT) foram inoculados, pela infiltração da suspensão bacteriana $\left(10^{3}\right.$ ufc/ml), isolado CNPH 68, em uma área aproximada de $2 \mathrm{~cm}^{2} \mathrm{e}$ as plantas mantidas em câmara de crescimento a $24^{\circ} \mathrm{C}$ com 16 $\mathrm{h}$ de luz e $80 \%$ de umidade relativa (UR). A população bacteriana foi determinada a cada $24 \mathrm{~h}$ após a inoculação até o início do aparecimento dos sintomas da doença. Amostras de $1 \mathrm{~cm}^{2}$ dos folíolos inoculados foram maceradas em $1 \mathrm{ml}$ de água destilada e esterilizada e o número de células bacterianas determinado pelo método de diluição em série. O delineamento experimental foi inteiramente casualisado com três repetições. Os genótipos foram comparados pela Área Abaixo da Curva de Progresso do Crescimento Populacional (AACPCP). Para a comparação dos genótipos a cada leitura, foi feita a transformação da população bacteriana em $\log (\mathrm{x}+1)$.

Para avaliação do tamanho, número de lesões e área lesionada, 15 DAT para vasos, as plantas foram inoculadas por infiltração, em uma área aproximada de $2 \mathrm{~cm}^{2}$ por folíolo, de uma suspensão de $10^{4} \mathrm{ufc} / \mathrm{ml}$ de Xcv, raça T2 e avaliados 15 dias após a inoculação, contando-se o número de lesões por folíolo e por área, e medindo-se o comprimento e a largura das lesões, com um paquímetro digital. O delineamento experimental foi inteiramente casualisado e foram usadas amostras de dez folíolos, por tratamento. A área lesionada foi calculada pela fórmula: área lesionada $=\pi$ (diâmetro da lesão $\div$ $2)^{2} \times$ (número de lesões) (Poulos et al., 1991).

O período latente de Xcv foi avaliado em casa de vegetação, em câmara de crescimento e no campo. As plantas foram aspergidas com uma suspensão de células bacterianas, $10^{6} \mathrm{ufc} / \mathrm{ml}$, em casa de vegetação e em câmara de crescimento, e $10^{7} \mathrm{ufc} / \mathrm{ml}$ no campo. A avaliação foi feita observando-se o tempo, em dias, após a inoculação até o início do aparecimento de sintoma em cada planta, até que $50 \%$ das plantas de cada genótipo apresentassem sintomas da mancha-bacteriana. $\mathrm{O}$ delineamento experimental foi em blocos ao acaso. Na casa de vegetação e na câmara de crescimento foram usadas três repetições de dez plantas (uma planta/vaso) e no campo, quatro repetições de dez plantas por parcela. Em casa de vegetação, após a inoculação, as plantas foram submetidas a um sistema automático de irrigação por microaspersores ligados por $30 \mathrm{~s} \mathrm{a}$ cada 30 min, por quatro dias consecutivos, em substituição à câmara úmida. A temperatura média foi de $22,4{ }^{\circ} \mathrm{C}$ e UR média de $68 \%$. Em câmara de crescimento as plantas foram mantidas a $24{ }^{\circ} \mathrm{C}$ com $16 \mathrm{~h}$ de luz e $80 \%$ de UR. O experimento no campo foi conduzido de agosto a outubro de 1999, na Embrapa Hortaliças, usando um espaçamento de $0,5 \mathrm{~m}$ entre plantas e 1,0 m entre linhas e a irrigação feita por aspersão. No período entre a inoculação e a avaliação a temperatura média foi de 25 ${ }^{\circ} \mathrm{C}$ e a UR do ar de $56 \%$.

\section{RESULTADOS E DISCUSSÃO}

A diferenciação dos genótipos de acordo com a AACPCP de Xcv foi significativa ( $\mathrm{p} \leq 0,05)$, sendo 'Ohio 8245', o genótipo que apresentou o menor valor e ' $\mathrm{CNPH} 416.81 .01 .02$ ' o que apresentou o maior valor da AACPCP (Tabela 1).

A partir da segunda avaliação, feita 48 h após a inoculação, foi possível verificar diferenças entre os genótipos resistentes ‘Ohio 8245' e 'Agrocica 30' e os suscetíveis ‘CNPH 401-08' e ‘CNPH 416.81.01.02', prevalecendo até a avaliação final, $168 \mathrm{~h}$ após a inoculação, quando os genótipos 'Ohio 8245' e ‘Agrocica 30' apresentaram uma população 100 e dez vezes menor em relação ao genótipo 'CNPH 401-08' e 'CNPH 416.81.01.02', respectivamente (Tabela 1). Os genótipos suscetíveis apresentaram um aumento da população bacteriana de aproximadamente 1.000 vezes entre a primeira e a última avaliação, contra um aumento de dez vezes nos genótipos 'Ohio 8245' e 'Agrocica 30'.

Os genótipos que apresentaram maiores populações bacterianas foram os mesmos que apresentaram maior severidade da mancha-bacteriana no campo (Silva et al., 1998a, 1998b), indicando que a população bacteriana alta está associada a maior intensidade de doença nestes genótipos. Resultado semelhante foi observado por Silva \& Lopes (1995), que relacionaram o aumento do nível populacional com 
Componentes da resistência à mancha-bacteriana e crescimento de...

TABELA 1 - Componentes da resistência e crescimento da população bacteriana de Xanthomonas campestris pv. vesicatoria, raça T2, em genótipos resistentes e suscetíveis de tomateiro (Lycopersicon esculentum)

\begin{tabular}{|c|c|c|c|c|c|c|c|c|c|}
\hline \multirow{2}{*}{$\begin{array}{l}\text { Genótipo de } \\
\text { tomateiro }\end{array}$} & \multicolumn{2}{|c|}{ População bacteriana } & \multicolumn{2}{|c|}{ Tamanho da lesão } & \multicolumn{2}{|c|}{ Número de lesões } & \multicolumn{3}{|c|}{$\begin{array}{c}\text { Período latente } \\
\text { (dias após inoculação) }\end{array}$} \\
\hline & ААСРСР & $\begin{array}{c}\text { (ufc/ml) } 168 \mathrm{~h} \\
\text { após inoculação }\end{array}$ & $\begin{array}{l}\text { Diâmetro } \\
(\mathrm{mm})\end{array}$ & $\begin{array}{c}\text { Área } \\
\left(\mathrm{mm}^{2}\right)\end{array}$ & Área & Folíolo & $\begin{array}{l}\text { Câmara de } \\
\text { crescimento }\end{array}$ & $\begin{array}{c}\text { Casa de } \\
\text { vegetação }\end{array}$ & Campo \\
\hline $\mathrm{CNPH} 401-08^{3}$ & $913,78 b^{1}$ & $1,6 \times 10^{8} \mathrm{a}^{2}$ & $0,60 \mathrm{a}$ & $4,51 \mathrm{a}$ & $49,10 \mathrm{a}$ & $221,70 \mathrm{a}$ & $6 \mathrm{c}$ & $6 \mathrm{~b}$ & $6 \mathrm{~b}$ \\
\hline CNPH $416.81 .01 .02^{3}$ & 1079,79 a & $6,1 \times 10^{7} \mathrm{~b}$ & $0,81 \mathrm{~b}$ & $5,08 \mathrm{a}$ & $28,90 \mathrm{~b}$ & $193,30 \mathrm{a}$ & $6 \mathrm{c}$ & $6 \mathrm{~b}$ & $6 \mathrm{~b}$ \\
\hline Ohio $8245^{4}$ & $785,54 \mathrm{c}$ & $1,4 \times 10^{6} \mathrm{~d}$ & $0,50 \mathrm{~b}$ & $1,02 \mathrm{~b}$ & $15,10 \mathrm{c}$ & $74,00 \quad b$ & $10 \mathrm{a}$ & $10 \mathrm{a}$ & $9 \mathrm{a}$ \\
\hline Agrocica $30^{4}$ & 838,30 bc & $2,0 \times 10^{6} \mathrm{~d}$ & $0,46 \mathrm{~b}$ & $0,39 \mathrm{~b}$ & $13,80 \mathrm{c}$ & 85,60 b & $8 \mathrm{~b}$ & $10 \mathrm{a}$ & 8 a \\
\hline Hawaii $7998^{5}$ & $929,87 \quad b$ & $4,3 \times 10^{6} \mathrm{c}$ & $0,59 \mathrm{~b}$ & $1,08 \mathrm{~b}$ & $13,40 \mathrm{c}$ & $58,00 \mathrm{~b}$ & $7 \mathrm{bc}$ & $7 \mathrm{~b}$ & $8 \mathrm{a}$ \\
\hline
\end{tabular}

${ }^{1}$ Letras iguais na mesma coluna, os genótipos não diferem significativamente entre si $(\mathrm{p}=0,01)$.

${ }^{2} \mathrm{Os}$ dados foram transformados em $\log (\mathrm{x}+1) \cdot{ }^{3} \mathrm{Genótipos} \mathrm{suscetíveis} \mathrm{à} \mathrm{mancha-bacteriana.}{ }^{4} \mathrm{Genótipos} \mathrm{resistentes} \mathrm{à} \mathrm{mancha-bacteriana.}$

${ }^{5}$ Padrão de resistência a raça T1 de Xcv.

aumento da intensidade da pinta-bacteriana [Pseudomonas syringae pv. tomato (Okabe) Young, Dye \& Wilkie] em cultivares suscetíveis de tomateiro.

Não foi estudado quais são os mecanismos que conferem resistência aos genótipos que apresentaram população de Xcv mais baixa, podendo a reação diferencial ser resultado de variações no número ou formato de estômatos, como verificado por McGuire et al. (1991), por limitações de nutrientes essenciais, presença de inibidores pré-formados, ou induzidos pela ação da bactéria, como proposto por Chand \& Walker (1964), ou ainda por outros fatores. Porém, ficou evidente que os genótipos portadores de resistência apresentam mecanismos que dificultam a multiplicação da bactéria em seus tecidos.

Os componentes de resistência, tamanho da lesão, número de lesões e área lesionada diferenciaram os genótipos resistentes e suscetíveis à mancha-bacteriana do tomateiro (Tabela 1). O mesmo foi verificado por Chand \& Walker (1964), monitorando a população de Pseudomonas lachrymans (Smith \& Bryan) Young et al. em plantas de pepino (Cucumis sativus L.).

Considerando o grande número de plantas que é avaliado em programas de melhoramento, visando resistência a doenças, o número de lesões por área e por folíolo foi o componente mais indicado para uso em trabalhos de seleção, devido a maior facilidade de avaliação, rapidez, eficiência e confiabilidade na seleção de genótipos portadores de resistência à mancha-bacteriana, quando comparado à área lesionada. Esta última apesar de ter apresentado bons resultados na diferenciação dos genótipos, apresenta uma avaliação demorada e ainda considera em seu cálculo, o tamanho da lesão, que é altamente influenciado pelas condições de ambiente, tornando a eficiência na seleção baixa.

Nos três ambientes, câmara de crescimento, casa de vegetação e campo, os genótipos 'Ohio 8245', 'Agrocica 30' e 'Hawaii 7998' apresentaram período latente maior que os genótipos suscetíveis 'CNPH 401-08' e 'CNPH 416.81.01.02' (Tabela 1). Nestes dois últimos genótipos, o aparecimento dos sintomas ocorreu aos 6 DAI, com $100 \%$ das plantas apresentando lesões, independente do ambiente, enquanto 'Ohio 8245 ' apresentou $50 \%$ das plantas sintomáticas aos 10 DAI tanto em casa de vegetação como em câmara de crescimento, e no campo aos 9 DAI. Os genótipos resistentes apresentaram $100 \%$ das plantas com sintomas aos 11 DAI e os suscetíveis aos 6 DAI (Tabela 1). Acredita-se que a variação no comprimento do período latente de acordo com o ambiente, tenha sido resultado da interação genótipo $\mathrm{x}$ ambiente, visto que as demais variáveis foram constantes. Como proposto por Amorim (1995), as diferenças no comprimento do período latente podem estar associadas à variedade da espécie hospedeira, à raça do patógeno e ao ambiente. $\mathrm{O}$ genótipo 'H7998', resistente à raça T1 de Xcv, apresentou período latente variável para a raça T2, em alguns casos diferindo dos genótipos suscetíveis. Este comportamento é esperado em sistemas controlados por vários genes, em que a manifestação fenotípica controlada pelo conjunto de genes de resistência é afetada pelo ambiente. Por isso, recomenda-se que as avaliações sejam feitas em ambiente controlado, concordando com Neervoort \& Parlevliet (1978).

Um período latente maior pode indicar uma maior resistência à colonização e, consequentemente, um menor número de ciclos do patógeno será produzido sobre uma determinada cultivar e menor a quantidade de doença no final do ciclo da planta. O genótipo que apresenta um maior período latente tem, assim, maior probabilidade de reduzir a taxa de progresso da doença, evitando a epidemia ou reduzindo o potencial de inóculo, quando as condições favoráveis à ocorrência da doença persistirem por períodos prolongados.

A correlação entre período latente e desenvolvimento da doença no campo, verificado para mancha-bacteriana e para outras doenças, o confirma como o principal componente de resistência à mancha-bacteriana do tomateiro, pela rapidez, facilidade e eficiência na avaliação do mesmo, em um grande número de genótipos. A importância da avaliação do período latente visando resistência a doenças ficou evidenciada em outros patossistemas (Neervoort \& Parlevliet, 1978; Parlevliet, 1979).

O efeito combinado dos quatro componentes, 
população final de Xcv, área lesionada, número de lesões e período latente ajudam a explicar a resistência dos genótipos 'Ohio 8245' e 'Agrocica 30' em relação aos genótipos suscetíveis 'CNPH 401-08' e 'CNPH 416.81.01.02', observadas nas avaliações da severidade da doença, por meio de notas.

\section{REFERÊNCIAS BIBLIOGRÁFICAS}

AMORIM, L. Colonização e reprodução. In: Bergamin Filho, A, Kimati, H. \& Amorim, L. (Eds). Manual de Fitopatologia: Princípios e Conceitos. Vol.1. 3 ed. São Paulo, Editora Agronômica Ceres. 1995. pp.309-324.

CHAND, J.N. \& WALKER, J.C. Relation of age of leaf and varietal resistance to bacterial multiplication in cucumber inoculated with Pseudomonas lachrymans. Phytopathology 54:49-50. 1964.

LOPES, C.A. \& QUEZADO-SOARES, A.M. Doenças bacterianas das hortaliças - diagnose e controle. Brasília: EMBRAPA - CNPH. 1997.

McGUIRE, R.G., JONES, J.B. \& SCOTT, J.W. Epiphytic populations of Xanthomonas campestris pv. vesicatoria on tomato cultigens resistant and susceptible to bacterial spot. Plant Disease 75:606-609. 1991.

NEERVOORT, W.J. \& PARLEVLIET, J.E. Partial resistance of barley to leaf rust, Puccinia hordei V. Analysis of the components of partial resistance in eight barley cultivars. Euphytica 27:33-39. 1978.

PARLEVLIET, J.E. Components of resistance that reduce the rate of epidemic development. Annual Review of Phytopathology 17:203222. 1979.

PLANK VAN DER, J.E. Plant diseases: Epidemics and control. New
York: Academic Press, 1963.

POULOS, J.M., REIFSCHNEIDER, F.J.B. \& COFFMAN, W.R. Heritability and gain from selection for quantitative resistance to Xanthomonas campestris pv. vesicatoria in Capsicum annuum L. Euphytica 56:161-167. 1991.

SAHIN, F. \& MILLER, S.A. Characterization of Ohio strains of Xanthomonas campestris pv. vesicatoria, causal agent of bacterial spot of pepper. Plant Disease 80:773-778. 1996.

SILVA, V.L. \& LOPES, C.A. Populações epifíticas de Pseudomonas syringae pv. tomato em cultivo comercial de tomateiro industrial. Fitopatologia Brasileira 20:179-183. 1995.

SILVA, V.L, QUEZADO-SOARES, A.M., GIORDANO, L.B. \& LOPES, C.A. Severidade da mancha-bacteriana em folhas e frutos de tomateiro. Fitopatologia Brasileira 23:217. 1998a (Resumo).

SILVA, V.L., QUEZADO-SOARES, A.M., LOPES, C.A. \& GIORDANO, L.B. Correlação da resistência de genótipos de tomateiro à mancha-bacteriana em campo e em casa de vegetação. Fitopatologia Brasileira 23:216. 1998b (Resumo)

SILVA-LOBO, V.L. Herança e componentes da resistência à manchabacteriana (Xanthomonas campestris pv. vesicatoria, raça T2) em tomateiro. (Tese de Doutorado) Brasília. Universidade de Brasília. 2000.

SOMODI, G.C., JONES, J.B. \& SCOTT, J.W. Populations of Xanthomonas campestris pv. vesicatoria in lesions of susceptible and resistant tomato genotypes. Plant Disease 75:357-360. 1991.

STALL, R.E. \& COOK, A.A. Multiplication of Xanthomonas vesicatoria and lesion development in resistant and susceptible pepper. Phytopathology 56:1152-1154. 1966.

WANG, J.F. Resistance to Xanthomonas campestris pv. vesicatoria in tomato. (PhD Thesis). Gainesville. University of Florida. 1992. 